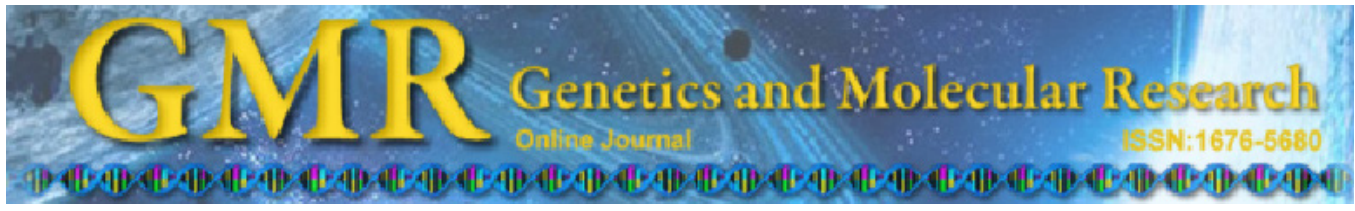

\title{
A multi-farm assessment of Greek black pig genetic diversity using microsatellite molecular markers
}

S. Michailidou ${ }^{1}$, A. Kalivas ${ }^{1,2}$, I. Ganopoulos ${ }^{1}$, E. Stea ${ }^{1}$, G. Michailidis ${ }^{3}$, A. Tsaftaris ${ }^{1,4}$ and A. Argiriou ${ }^{1}$

${ }^{1}$ Institute of Applied Biosciences, Center for Research and Technology Hellas, Thermi, Greece

${ }^{2}$ Cotton and Industrial Plants Institute,

National Agricultural Research Foundation, Sindos, Greece

${ }^{3}$ Laboratory of Physiology of Reproduction of Farm Animals,

Department of Animal Production, School of Agriculture,

Aristotle University of Thessaloniki, Thessaloniki, Greece

${ }^{4}$ Department of Genetics and Plant Breeding, School of Agriculture,

Aristotle University of Thessaloniki, Thessaloniki, Greece

Corresponding author: Anagnostis Argiriou

E-mail: argiriou@certh.gr

Genet. Mol. Res. 13 (2): 2752-2765 (2014)

Received January 11, 2013

Accepted July 15, 2013

Published April 14, 2014

DOI http://dx.doi.org/10.4238/2014.April.14.4

ABSTRACT. Local breeds are important for the maintenance of genetic diversity and future food security. Nowadays, the worldwide distribution of pigs is dominated by a few breeds, tending towards a severe loss of pig biodiversity. Thus, it is critical to maintain distinct populations of pig breeds. The Greek black pig, a breed raised locally and known for the high quality of its meat for cured products, is the only traditional indigenous pig breed reared in Greece. We investigated the genetic diversity, based on microsatellite analysis, of the Greek black pig and evaluated its genetic uniqueness. One hundred and three pigs from 12 Greek farms were analyzed using 11 microsatellites. The 
total number of alleles amounted to 135 , with a mean number of alleles per locus of 12.27, ranging between 10 and 16 alleles. The observed heterozygosity ranged from 0.363 to 0.825 per locus. The expected heterozygosity ranged from 0.471 to 0.707 . The inbreeding coefficient ranged from -0.329 to 0.229 . We conclude that the Greek black pig, despite its low population size, has a high degree of genetic variability, which will be useful for breeding programs aimed at maintaining longterm survival of this ancient breed.

Key words: Greek black pig; Microsatellite; Conservation

\section{INTRODUCTION}

Local breeds are important for the maintenance of genetic diversity and future food supply as stated by the United Nations Food and Agricultural Organization (FAO, 2007). Moreover, domesticated animal breeds are often regarded as part of the cultural heritage of lo$\mathrm{cal}$ and national communities. Among them, pigs are of particular interest since they have been used as a source of meat and lard to nourish local populations since ancient times, particularly in the mountainous areas of the Mediterranean basin.

Nowadays, the worldwide distribution of pigs is dominated by just five breeds, all of them from Europe or the United States: Large White (117 countries), Duroc (93 countries), Landrace (91 countries), Hampshire (54 countries), and Piétrain (35 countries) (FAO, 2006). However, across the world, nearly 400 breeds have been exploited, with the largest number of breeds being found in Asia and Europe (Groeneveld et al., 2010).

There are actually more than 190 million pigs raised in Europe in total, and more than 920,000 of them are located in Greece (FAO, 2008). Europe has a large number of local pig breeds, 165 breeds in total (FAO, 2006). However, the vast majority of animals in production systems belong to few intensively selected breeds (Nidup and Moran, 2011), which are preferred by producers due to the higher profit they provide their farms compared to autochthonous races. Consequently, many of the local breeds are now in danger of extinction, and others are threatened by inefficient use or loss due to cross-breeding (FAO, 2006; Nidup and Moran, 2011). The main reasons for loss of farm animal genetic resources are the introduction of exotic germplasm, poor agricultural policies, restriction of development to a few breeds, degradation of ecosystems, natural disasters, and political unrest and instability (FAO, 1998).

This severe loss of biodiversity has markedly affected animal production systems, especially in marginal areas (Guastella et al., 2010). To better comprehend the existing situation, it should be noted that according to FAO (2007), a comparison at the species level revealed that horses $(23 \%)$, followed by rabbits $(20 \%)$, pigs $(18 \%)$, and cattle $(16 \%)$, are the mammalian species that have the highest proportions of at-risk breeds. Risk status depends on several factors such as the size and the structure of population, the current and predicted future population trends, and the geographical distribution of the population (Groeneveld et al., 2010).

During the last decades, the biased selection of high-performance pig breeds in combination with the displacement of extensive production systems has led to a dramatic decrease in gene pool, resulting in a reduction of genetic variation among populations and creating a 
severe loss of useful and desirable traits. Attempts to reverse this negative trend have led to research on the preservation and exploitation of local animal breeds, with efforts to identify and reintroduce potentially important genetic traits that have been overlooked by globalized production systems (Guastella et al., 2010). The need perceived internationally to conserve biodiversity, in parallel with increased public sensitivity to environmental problems caused by intensive pig farms, has encouraged the policy of the recovery and preservation of native species (Scali et al., 2012) particularly when these species are connected to high-quality traditional meat products. Thus, it is critical to maintain distinct populations of pig breeds, where all activities in the European pig breeding industry should aim at the conservation of local pig breeds, finding new sources of genetic variants that must include rare autochthonous breeds, not only for the genetic conservation of breeds but also to respond to potential changes in consumer demands and to satisfy their needs.

The introduction of high-yielding improved pig breeds under intensive production systems has replaced, almost to the point of disappearance, the traditional production system based on the native pig breed. Moreover, consumers' negative perception of animal fat in the second part of the 20th century and the low growth rate and feed conversion efficiency of many local breeds almost led to the extinction of the Mediterranean black pig.

The Greek black pig is the only traditional indigenous pig breed raised in Greece until the late 1960s. Its domestication is lost in history, where references are made in ancient texts such as the Iliad and Odyssey. The Greek black pig was raised to provide meat and leather to almost every Greek family living in urban regions till recently. It is a product of natural selection that was able to adapt to different and harsh environmental conditions. Currently, there are very few breeders in Greece raising this breed intensively, with their farms counting almost 300 sows in total, which renders the Greek black pig on the list of endangered autochthonous breeds. These small nuclei are spotted in all continental Greece but mainly concentrated in northern and central Greece. Concerning the characteristics of the Greek black pig, they resemble those of the black Mediterranean pig with high rusticity. Sows have a seasonal reproductive activity and produce two litters per year, consisting of $8.48 \pm 1.94$ piglets at birth (Laliotis, 2001). They reach reproductive maturity relatively late, at the age of 8 months when the average weight is $80-90$ $\mathrm{kg}$. Body weight of piglets at weaning is approximately $7.69 \pm 0.69 \mathrm{~kg}$. Only $80 \%$ of piglets born reach slaughter age, because there are losses due to exogenous factors such as carnivores and unfavorable environmental conditions (Laliotis, 2001). Some of the most important production and reproductive traits of the indigenous black pig are listed in Table S1.

Pigs are usually slaughtered at 240-300 days and a carcass of more or less $60 \mathrm{~kg}$ is obtained. In general, the Greek black pig has excellent meat quality and cured meat products of great organoleptic characteristics, which makes this breed special among all other pig breeds raised in Greece. Besides, its great adaptability makes Greek black pig breeding ideal for regions with harsh environmental conditions.

One of the main problems nowadays is that breeding stocks tend to be isolated by farm, and the farmers each tend to apply their own breeding strategies, which in some cases may even include crossing with commercial breeds. While crossbreeding may potentially enhance production traits, it simultaneously threatens the heritage status of the breed and, with that, the higher value of its meat. For the smallest farms in particular, there is a concern of high inbreeding levels and related risks of inbreeding depression and subsequent decrease in the productivity of the pigs. 
All these factors directly threaten the persistence of this breed, which could represent an important socioeconomic influence in the continental Greek region. However, to design an effective conservation program, a detailed genetic study of the Greek black breed diversity is a necessary first step.

The objective of this study was to investigate for the first time in Greece the genetic diversity, based on microsatellite analysis, of the Greek black pig and to evaluate its genetic uniqueness among several pig populations located in Greece.

\section{MATERIAL AND METHODS}

\section{Sample collection/population}

A total of 103 pig samples were collected and analyzed from various farms spotted in different Greek regions. Specifically, 88 pig samples were collected from 12 farms distributed in continental Greece (Figure 1), and moreover, 2 wild boar samples hunted in different areas were included in the study. In addition, apart from the native autochthonous samples, 6 pig samples from Sicily Italy of the Nero di Nebrodi breed and 7 pig samples from commercial breeds [Large White (3 samples), Landrace, Duroc, Pietrain (TITAN) and Yorkshire] were collected and analyzed for comparison purposes.

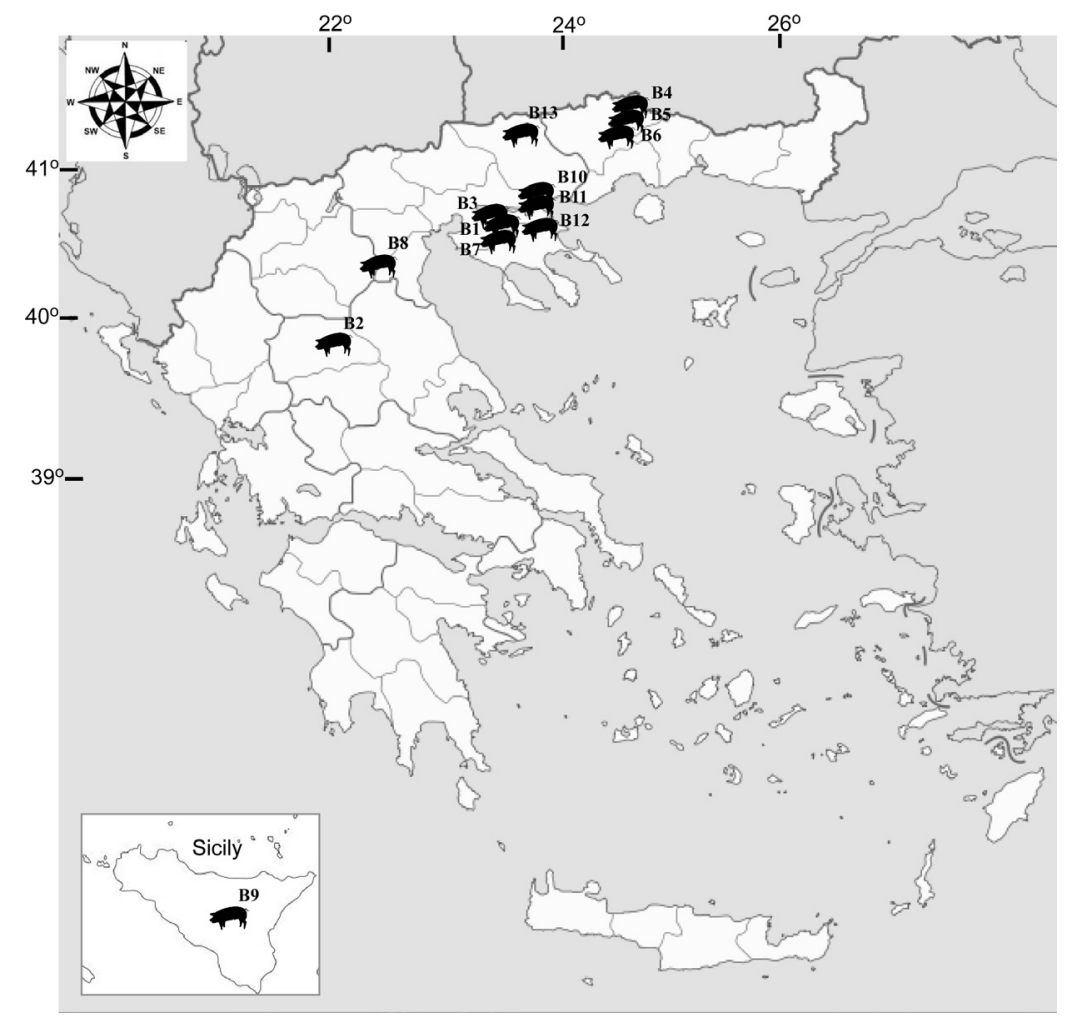

Figure 1. Geographical map indicating the distribution of the selected Greek farms. 
Hair samples were collected from individuals and stored in a freezer $\left(-20^{\circ} \mathrm{C}\right)$ until use. Genomic DNA was extracted from hair tissue using the NucleoSpin Tissue kit (Macherey-Nagel, Germany) according to manufacturer protocol. DNA quantity and purity were determined by absorbance at 260 and $280 \mathrm{~nm}$ using a spectrophotometer (BioPhotometer, Eppendorf, Hamburg, Germany), and DNA integrity was examined by electrophoresis on a $1 \%$ agarose gel.

\section{Microsatellite genotyping/markers}

Eleven microsatellites were selected from the PIGMAP project developed by the Roslin Institute, Edinburg. These markers were selected for their high degree of polymorphism, absence of null alleles, size and location on the porcine genome on different chromosomes. Forward primers were fluorescently labeled at the $5^{\prime}$ end, using IRD700 and IRD800 (Table S2). All animals were genotyped for the 11 microsatellite markers. Amplification of PCR products was performed on an Eppendorf Mastercycler EP Gradient, using approximately $50 \mathrm{ng}$ genomic DNA as template, 10X PCR buffer (KAPA Biosystems, Boston, USA), $10 \mu \mathrm{M}$ fluorescently labeled primers, $10 \mathrm{mM}$ dNTP each and $1 \mathrm{U}$ Taq DNA polymerase (KAPA Biosystems) in a $20-\mu \mathrm{L}$ total volume reaction. PCR conditions were: $95^{\circ} \mathrm{C}$ for $4 \mathrm{~min}$, followed by 35 cycles of $94^{\circ} \mathrm{C}$ for $30 \mathrm{~s}$, annealing temperature of each primer set for $30 \mathrm{~s}$ (optimized PCR conditions for each primer set are presented in Table 1) and $72^{\circ} \mathrm{C}$ for $30 \mathrm{~s}$, and a final extension period at $72^{\circ} \mathrm{C}$ for $10 \mathrm{~min}$. PCR products were resolved by electrophoresis on $1 \%$ agarose gel, visualized with ethidium bromide and imaged under UV illumination.

After the amplification of PCR products, two multiplex mixes were created according to the size range of PCR products and the IRDye. The first mix consisted of SW122, SW632, SWR1941, SW295, SO226, and SO355 and the second mix of SW122, SW911, SW742, SW2008, SW787, and SW902 markers. Stop buffer containing $47.5 \mathrm{~mL}$ deionized formamide, $2 \mathrm{~mL} 0.5 \mathrm{M}$ EDTA, $0.5 \mathrm{~mL} \mathrm{H}_{2} \mathrm{O}$, and $40 \mathrm{mg}$ bromophenol blue was added to PCR products in a 1:3 proportion, and the mixes were then diluted 300 times with distilled water.

Electrophoresis was run on a DNA Analyzer (Model 4300, LI-COR Biosciences) according to manufacturer instructions. All amplicons were automatically sized and classified using the Saga ${ }^{\mathrm{GT}}$ software.

\section{Statistical analysis}

\section{Microsatellite variation and genetic diversity within farms}

The percentage of polymorphic loci $(\mathrm{P})$, effective numbers of alleles $\left(N_{\mathrm{E}}\right)$, gene diversity (expected heterozygosity, $H_{\mathrm{E}}$ ), and Shannon diversity index (I) were calculated using PopGene32 (Yeh et al., 1999). We used the hierarchical rarefaction method available in HPRARE (Kalinowski, 2005) to calculate, in addition to the above parameters, allelic richness (AR), private allelic richness (pAR; alleles which are unique to a particular population), and the inbreeding coefficient $\left(F_{\text {IS }}\right)$. As null alleles were suspected in some loci, allelic frequency estimation and comparison between observed and Hardy-Weinberg expected heterozygote frequencies were computed by the maximum likelihood method described by Kalinowski and 
Taper (2006). Conformance to Hardy-Weinberg equilibrium was determined by assessing the significance of the $\mathrm{F}_{\mathrm{IS}}$ values by means of Fisher exact tests implemented in GENEPOP with specified Markov chain parameters of 5000 dememorization steps, followed by 1000 batches of 5000 iterations per batch. The sequential Bonferroni correction was applied to obtain critical confidence limits for multiple comparisons, with an initial probability of $\mathrm{P}=0.05$.

\section{Genetic divergence between farms}

The program FSTAT was used to calculate $\mathrm{F}_{\mathrm{ST}}$ (Weir and Cockerham, 1984) across all populations. A total of 1000 randomizations were used to determine the statistical significance of the estimates; means and significant values over loci, populations, and subdivisions were obtained by jackknifing. The GENEPOP software (Raymond and Rousset, 1995) (http://genepop.curtin.edu.au/) was used to test for linkage disequilibrium between all pairs of loci after Bonferroni correction. The hierarchical distribution of genetic variation and within populations for both markers was also characterized by an analysis of molecular variance (AMOVA; Excoffier et al., 1992; Michalakis and Excoffier, 1996). We conducted a hierarchical AMOVA using the GENALEX 6 software (Peakall and Smouse, 2006). The tests were implemented using estimates of $\Phi_{\mathrm{ST}}$ based on distances calculated from allelic data. Tests of significance were performed using 9999 permutations within the total dataset. Unbiased genetic distances between populations were estimated according to Nei (1978) using PopGene32 (Yeh et al., 1999). The relationships between populations were initially investigated by an unweighted pair group method using arithmetic means (UPGMA) dendrograms based on Nei's genetic distances (Nei, 1978) which were constructed for microsatellite markers. Genetic relationships between populations were studied via principal component analysis (PCA) using GenAlEx 6.41. A modelbased Bayesian clustering method was applied to microsatellite data to infer genetic structure and define the number of clusters (gene pools) in the dataset using the software STRUCTURE version 2.3.4 (Pritchard et al., 2000). We ran the program using the admixture model and the correlated allele frequencies option, which are considered most appropriate for detecting structure among populations that are likely to be similar due to migration or shared ancestry (Falush et al., 2003). The STRUCTURE 2.3.2 software uses a Markov chain-Monte Carlo procedure to infer unstructured subpopulations, without considering prior classification within the sample. The proportional membership of each cluster was estimated on the basis of its genotype.

\section{RESULTS}

\section{Microsatellite variation and genetic diversity within farms}

The total number of alleles found for the 11 microsatellite markers analyzed in the 15 pig populations amounted to 135 with a mean number of alleles per locus of 12.27, ranging between ten (SW911) and 16 (SW742) alleles. The observed heterozygosity $\left(H_{\mathrm{O}}\right)$ level ranged from 0.363 for locus S0355 to 0.825 for locus SW295. The expected heterozygosity $\left(H_{\mathrm{E}}\right)$ ranged from 0.471 (S0355) to 0.707 (SW122). The inbreeding coefficient $\left(F_{\text {IS }}\right)$ ranged from -0.329 (SW295) to 0.229 (S0355). At three loci (S0226, SW295, and SW787) the $\mathrm{F}_{\mathrm{IS}}$ value deviated significantly from zero. The genetic differentiation among population parameters $\mathrm{F}_{\mathrm{ST}}$ also varied among loci, ranging from 0.171 (SW122) to 0.313 (S0355) (Table 1). The number of alleles per locus independent of 
sample size AR (the allelic richness) ranged from 2.09 (Farm 5) to 5.83 (Farm 8). Private alleles were also noticed and on the average private allelic richness (pAR) amounted to about $10 \%$ of total AR. The expected heterozygosity was the highest in Farm 8 (0.742) and the lowest in Farm 5 (0.386). At the population level, microsatellites indicated high levels of genetic variation in Farm 1, Farm 4, and Farm 8 and relatively high levels in the eight remaining populations (Table 2). Six of fifteen populations showed significant negative $F_{\text {IS }}$ values, indicating heterozygote excess in Greek black pig farms especially in the Farm 5 population $\left(F_{\text {IS }}=-0.407\right.$, Table 2$)$.

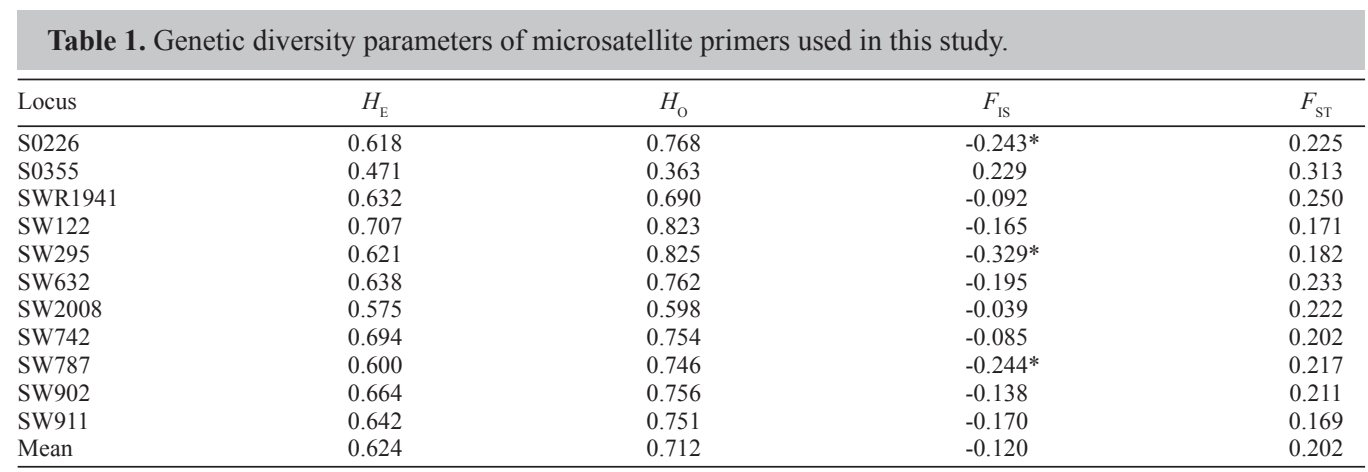

*Values deviated significantly from zero.

Table 2. Genetic diversity among the 15 pig farms as revealed by microsatellite analysis.

\begin{tabular}{|c|c|c|c|c|c|c|c|}
\hline Population name & $N_{\mathrm{A}}$ & $N_{\mathrm{E}}$ & $\mathrm{AR}$ & I & $H_{\mathrm{O}}$ & $H_{\mathrm{E}}$ & $F_{\text {IS }}$ \\
\hline Farm 1 & 4.091 & 3.199 & 4.09 & 1.221 & 0.800 & 0.656 & -0.063 \\
\hline Farm 2 & 3.455 & 2.625 & 3.45 & 1.005 & 0.652 & 0.562 & $-0.153 *$ \\
\hline Farm 3 & 4.455 & 3.140 & 4.45 & 1.255 & 0.803 & 0.659 & $-0.227 *$ \\
\hline Farm 4 & 4.636 & 3.330 & 4.64 & 1.321 & 0.591 & 0.684 & 0.132 \\
\hline Farm 5 & 2.091 & 1.818 & 2.09 & 0.602 & 0.545 & 0.386 & $-0.407 *$ \\
\hline Farm 6 & 3.364 & 2.686 & 3.36 & 1.009 & 0.591 & 0.565 & -0.030 \\
\hline Farm 7 & 3.818 & 3.171 & 3.82 & 1.181 & 0.864 & 0.642 & $-0.362 *$ \\
\hline Farm 8 & 7.273 & 4.500 & 5.83 & 1.629 & 0.737 & 0.742 & -0.052 \\
\hline Farm 9 & 4.545 & 3.499 & 4.55 & 1.311 & 0.773 & 0.685 & $-0.214 *$ \\
\hline Farm 10 & 5.273 & 3.637 & 4.78 & 1.385 & 0.692 & 0.693 & -0.181 \\
\hline Farm 11 & 3.364 & 2.557 & 3.36 & 1.012 & 0.808 & 0.582 & -0.139 \\
\hline Farm 12 & 5.000 & 3.604 & 4.71 & 1.293 & 0.729 & 0.631 & -0.203 \\
\hline Farm 13 & 4.000 & 2.686 & 4.00 & 1.086 & 0.726 & 0.577 & -0.043 \\
\hline Wildboar & 3.091 & 2.897 & 3.09 & 1.047 & 0.773 & 0.614 & $-0.236^{*}$ \\
\hline International & 5.182 & 3.707 & 5.18 & 1.373 & 0.602 & 0.677 & 0.056 \\
\hline Mean & 4.242 & 3.137 & 4.09 & 1.182 & 0.712 & 0.624 & -0.141 \\
\hline
\end{tabular}

*Significant negative $F_{\text {IS }}$ values.

\section{Genetic divergence between farms}

Genetic differentiation is an important index to evaluate the population genetic structure of a species. With regard to linkage disequilibrium, there was only one population (Farm $8)$ that showed one locus combinations with significant values $(\mathrm{P}<0.05)$ after Bonferroni correction. According to AMOVA of the microsatellite data set, there were highly significant $(\mathrm{P}<$ $0.001)$ genetic differences between the eleven pig populations. Seventeen percent of the total 
genetic diversity was attributed to between-population differentiation. Thus, AMOVA ( $F_{\text {ST }}$ $=0.115)$ also supported the results of Nei gene diversity statistics (Nei, 1978) and Shannon diversity index, indicating genetic differentiation between populations (Table 3). To elucidate further gene differentiation between populations, pairwise $F_{\mathrm{ST}}$ values were evaluated (Table 4). The largest genetic difference (0.291) occurred between Farm 13 and Farm 5 populations and the least (0.058) between Farm 9 and Farm 8 populations.

Table 3. Microsatellite analysis of molecular variance (AMOVA) for the fifteen pig populations.
\begin{tabular}{lccccc}
\hline Source & d.f. & SS & MS & Est. Var. & $\%$ \\
\hline Among populations & 14 & 162.245 & 11.589 & 0.529 & $11 \%$ \\
Among individuals & 88 & 398.707 & 4.531 & 0.447 & $10 \%$ \\
Within individuals & 103 & 374.500 & 3.636 & 3.636 & $79 \%$ \\
Total & 205 & 935.451 & & 4.612 & $100 \%$ \\
\hline
\end{tabular}

Relatedness between populations was illustrated by a dendrogram using the UPGMA algorithm based on Nei's distance (Nei, 1978). A microsatellite-based dendrogram grouped the fifteen populations into three main clusters (Figure 2). The Farm 5 population formed a separate cluster showing less similarity to the other populations studied. The other clusters were further divided into subclusters; the first consisting of Farms 1, 2, 3, 4, 6, 7, and 9, wild boar and International (first subgroup) and the second of Farms 8, 10, 11, 12, and 13 (second subgroup).

Furthermore, PCA results illustrated four major clusters, which was congruent with the UPGMA dendrogram (Figure 3), especially regarding the clear separation of Farm 2 and the formation of a large cluster corresponding to the remaining populations. The first two principal coordinates accounted for $45.99 \%$ of the total variation (Figure 3 ).

To measure the population structure and degree of admixture, we applied the STRUCTURE algorithm. All runs from $\mathrm{K}=2$ to $\mathrm{K}=9$ showed a pattern allowing a meaningful interpretation. However, the highest log likelihood score was obtained for $\mathrm{K}=6$. Thus, the status $\mathrm{K}$ $=6$ corresponded to the picture of breed formation, whereas the status $\mathrm{K}=9$ represented a higher resolution of the actual state of the composition of the local Greek black pig farms (Figure 4).

\section{DISCUSSION}

In the present study, as a first conservation approach, we characterized the genetic diversity of the Greek black pig using eleven microsatellite molecular markers. The advantages of microsatellite markers for evaluating diversity have been known for a long time; difficulties, however, have been recognized in harmonizing results from different laboratories, which requires the standardization of allele size (Ollivier, 2009). In our study, microsatellite markers showed a considerably high degree of genetic polymorphism within and between populations on the basis of their allele numbers per locus $\left(N_{\mathrm{A}}\right)$ and their genetic heterozygosity $\left(H_{\mathrm{E}}\right)$. The mean number of alleles per locus $\left(N_{\mathrm{A}}=12.27\right)$ was the highest among several European and Asian breeds including 11 European pigs breeds $\left(N_{\mathrm{A}}=10.6\right)$ (Laval et al., 2000), the Taihu pig breed $\left(N_{\mathrm{A}}=8\right)$ (Fan et al., 2002), the Iberian pig breed $\left(N_{\mathrm{A}}=7.2\right)$ (Fabuel et al., 2004), the Cinta Senese pig breed $\left(N_{\mathrm{A}}=9\right)$ (Scali et al., 2012), the Nero Siciliano pig breed $\left(N_{\mathrm{A}}=9.96\right)$ (Guastella et al., 2010), six Chinese indigenous pig breeds $\left(N_{\mathrm{A}}=10.35\right)$ (Wang et al., 2011), and the Croatian Turopolje pig breed $\left(N_{\mathrm{A}}=7.7\right)$ (Druml et al., 2012). However, the mean number 
S. Michailidou et al.

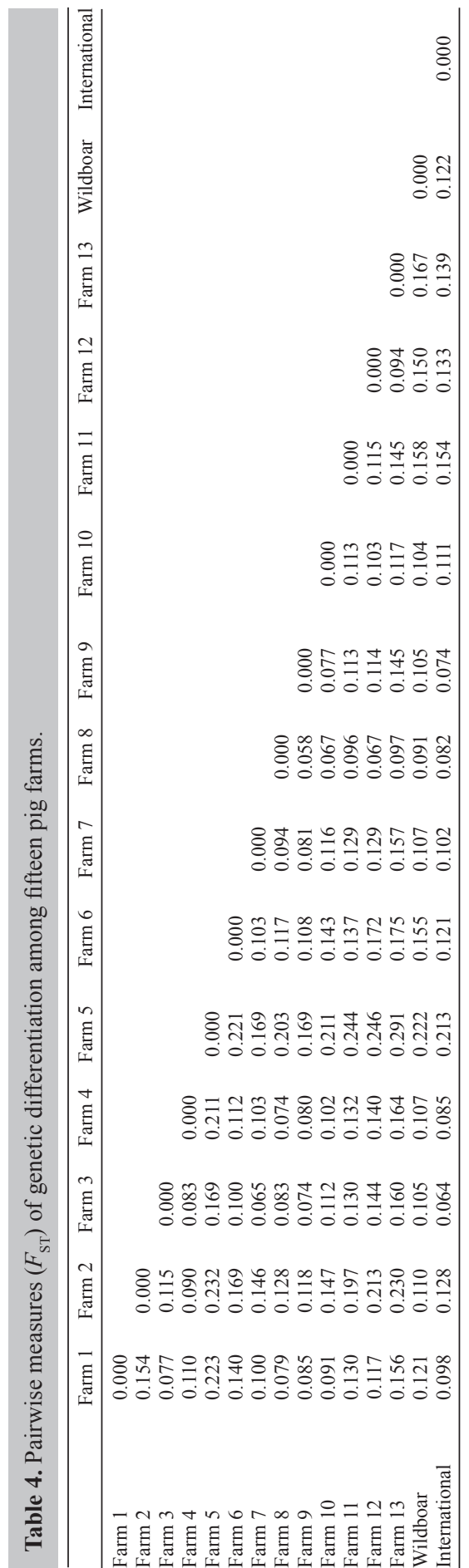




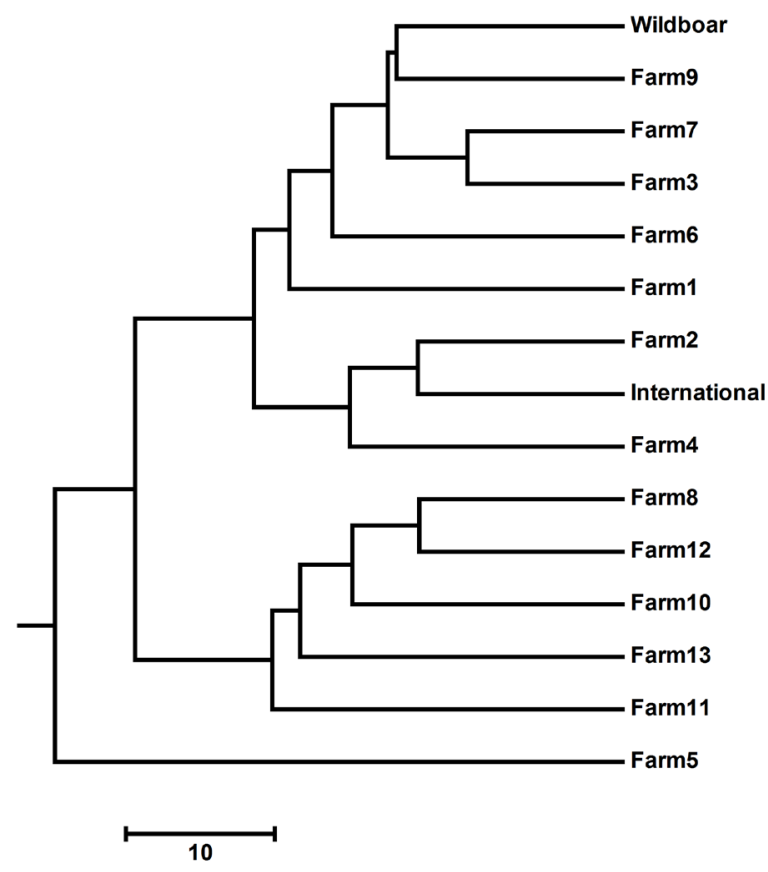

Figure 2. UPGMA dendrogram, derived from Nei's (Nei, 1978) unbiased genetic distances, showing the relationships among the examined populations of pigs using microsatellite datasets. Branch lengths are proportional to genetic distances. The bootstrap values (1000 replicates) are given as a percentage at nodes.

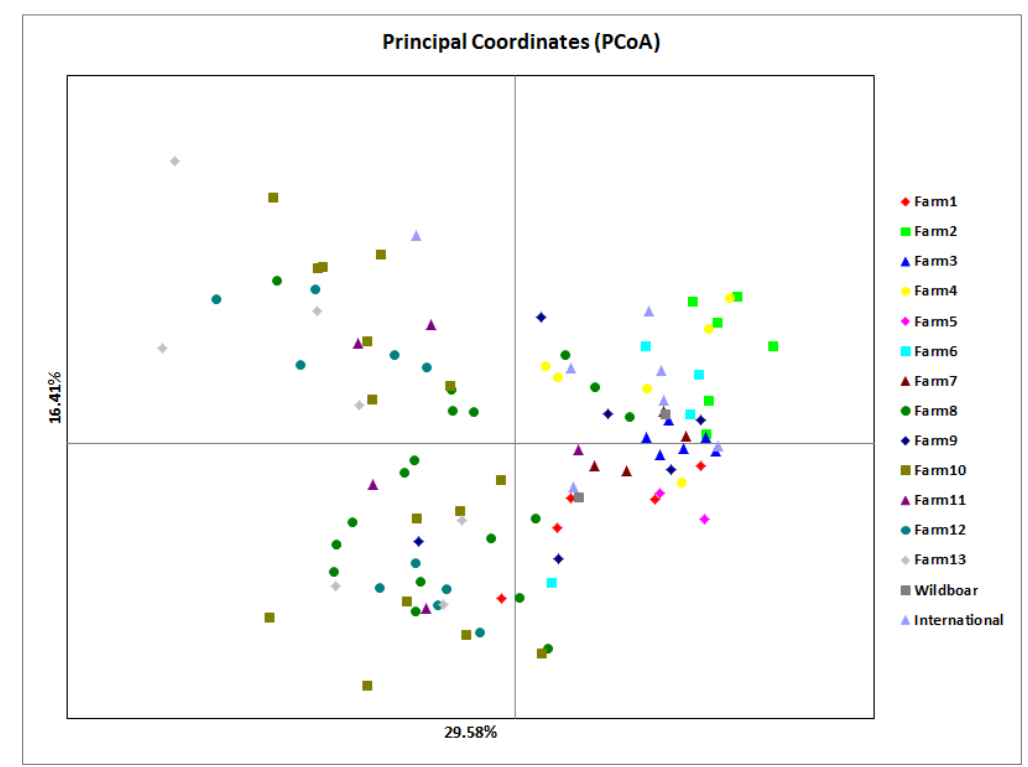

Figure 3. Scatter plot of the first and second principal coordinates based on the molecular variation of microsatellite markers for fifteen pig populations. 


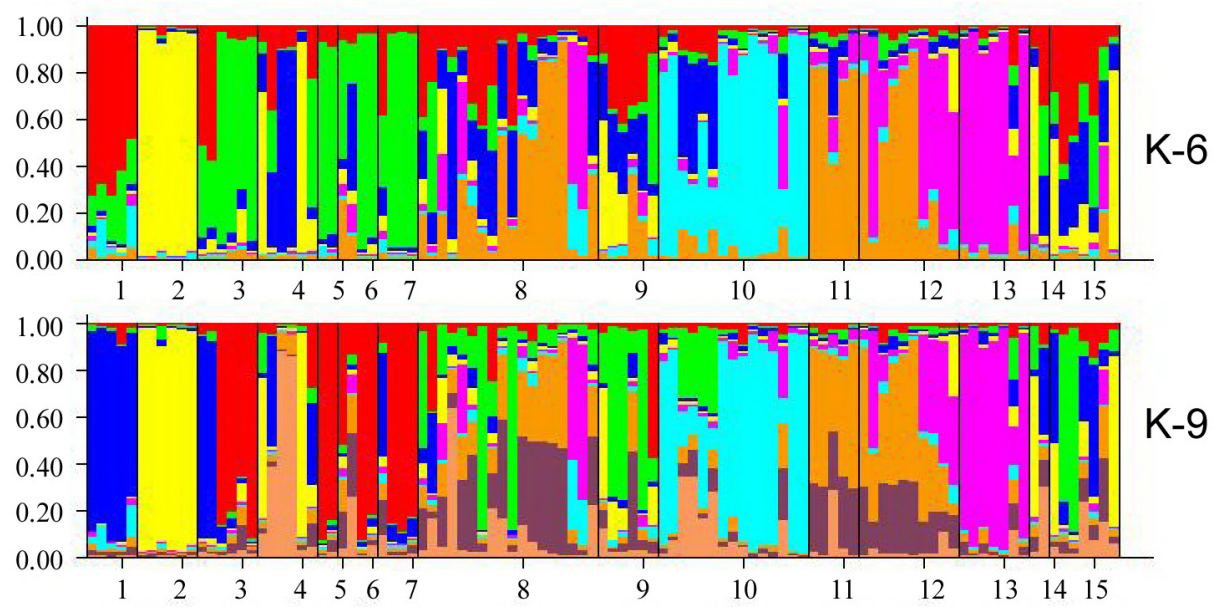

Figure 4. Bayesian clustering (103 animals) using 11 microsatellite markers. The clustering was obtained from STRUCTURE, for a model with admixture and correlated allele frequencies between groups; each pig is represented by a single vertical line broken into $\mathrm{K}$ colour segments, with lengths proportional to the estimated membership of the inferred cluster; only graphical presentations with the best fits towards data $(K=2$ and $K=5)$.

of alleles per locus was significantly higher in several Chinese indigenous pig populations $(\mathrm{NA}=24.8)$ (Li et al., 2004). In general, $N_{\mathrm{A}}$ ranged between 7.2 in the Iberian breed (Fabuel et al., 2004) to 24.8 in several Chinese indigenous pig populations (Li et al., 2004). Looking across populations, this significant parameter, alongside the variation in allelic richness $(\mathrm{AR}=$ 4.09), is very critical for the conservation of the Greek black pig, since it allows individuals to adapt to unpredictable environmental conditions. The mean gene diversity within farms in our study $\left(H_{\mathrm{E}}=0.624\right)$ was in general congruent with most studies; $H_{\mathrm{E}}$ ranged from 0.533 in 11 European pigs breeds (Laval et al., 2000) to 0.706 in the Nero Siciliano pig breed (Guastella et al., 2010). This value is significant since it is an indicator of a population's health, implying a rich variation in its gene pool. However, the mean observed heterozygosity within farms in our study $\left(H_{\mathrm{O}}=0.712\right)$ was higher than any other corresponding values in similar studies, with this parameter ranging between 0.476 for the Taihu pig breed (Fan et al., 2002) and 0.686 for six Chinese indigenous pig breeds (Wang et al., 2011). Observed heterozygosity in most farms was higher than expected, and this was in agreement with only a few studies concerning eleven European pig breeds (Laval et al., 2000), six Chinese indigenous pig breeds (Wang et al., 2011) and the Guadyerbas pig breed (Rodrigáñez et al., 2008). According to Wang et al. (2011), several factors such as non-random mating, Wahlund effect, sampling error, and the lower proportion of male individuals may cause deviation from Hardy-Weinberg equilibrium and higher $H_{\mathrm{O}}$ than $H_{\mathrm{E}}$. Thus, although there were very few individuals of the Greek black pig and their geographical extension was quite limited, the genetic variation within farms was very high. This observation is in agreement with other studies in the Nero Siciliano pig (SanCristobal et al., 2006; Davoli et al., 2007; Guastella et al., 2010). According to Guastella et al. (2010), this is a rather frequent condition for populations reared in extensive systems where there is no systematic selection and planned mating.

Unlike most studies, inbreeding coefficient $\left(F_{\text {IS }}\right)$ between populations was signifi- 
cantly lower than zero $\left(F_{\text {IS }}=-0.141\right)$, indicating the high heterozygosity of individuals and as a consequence the high genetic variability of this breed. Negative values of inbreeding coefficient were also observed in the Serbian Mangalica breed and in a Turopolje herd, suggesting an excess of heterozygotes due to non-random mating (Druml et al., 2012). As far as we know, the heterozygote excess in our study is among the highest ever reported. These results are very important since the maintenance of genetic variability is the main objective of conservation programs (Fabuel et al., 2004).

As expected for an endangered species with a restricted geographical range, such as the Greek black pig, the within-breed fixation index value $\left(F_{\mathrm{ST}}\right)$ showed a relatively low extent of genetic differentiation (mean $F_{\mathrm{ST}}=0.202$ ) which is comparable to other related studies reported by Scali et al. (2012) (mean $F_{\mathrm{ST}}=0.285$ ), Li et al. (2004) (mean $F_{\mathrm{ST}}=0.270$ ), Fan et al. (2002) (mean $\left.F_{\mathrm{ST}}=0.180\right)$, Fabuel et al. (2004) (mean $\left.F_{\mathrm{ST}}=0.129\right)$, Laval et al. (2000) (mean $\left.F_{\mathrm{ST}}=0.270\right)$ and Wang et al. (2011) (mean $\left.F_{\mathrm{ST}}=0.188\right)$.

Principal coordinates and Bayesian clustering showed admixed individuals in nearly all populations. Only one pig population (Farm 2) was distinguishable, indicating a stronger pattern of similarity among individuals than for others. As such, individuals from this cluster should be used in planned matings to preserve and spread the Greek black pig's typical production and reproductive traits. A different approach is that individuals belonging to different clusters could be used in planned matings to maintain a good level of genetic variability and rusticity (stress-resistance) and avoid excessive inbreeding (Guastella et al., 2010). Interestingly, the UPGMA dendrogram showed that Farm 2 was close to the wild boar. This is particularly surprising due to the fact that there is no mating between these two populations. In fact, it is rather remarkable because we can assume that the Greek black pig is a primitive breed and resembles the ancient Mediterranean black pig, which probably has common ancestors with the wild boar. However, further investigations should be conducted because this explanation is based on a limited number of individuals and it should be confirmed on a wider population size.

Overall, pig breeders in Greece should aim at designing the appropriate conservation strategies to avoid loss of genetic diversity. However, it should also be noted that the maintenance of genetic diversity is not the only criterion in extensive pig production systems. Decisions on choice of breeds should also take into account traits of economic value, specific adaptive features, distinct phenotypes, role of breed in local production systems, population size, level of endangerment, and availability of resources and infrastructure in the region where a breed is located (Nidup and Moran, 2011).

Unfortunately, although we analyzed a relatively large number of localities compared to the actual population size of the breed, a limited aspect of our analyses was that all genetic data were based on samples collected from local populations, which did not ensure that all genetic variability of this breed was actually sampled. Also, because of the relatively small sample sizes selected from the fifteen local populations, it is not possible to guarantee that all alleles have been considered for the analysis; this means that by adding more samples in the analysis, it might be quite possible to discover new alleles that should be taken into account, probably modifying the results reported here. However, we believe that our samples cover most of the genetic diversity of this breed.

The results of this study showed that the Greek black pig, despite its small population size has a high level of genetic variability. This variability in alleles should be preserved for creating a gene pool to conserve this breed's characteristics for the future. It is evident that the 
long-term survival of this breed depends on restoring and improving gene flow between all populations located in Greece, a management task that can be accomplished only through the cooperation of molecular researchers and animal breeders.

\section{ACKNOWLEDGMENTS}

Research supported by the Programme MED 2007 - 2013 - "Animal Breeding: Quality Biodiversity Innovation Competitiveness (QUBIC)" (\#1G-MED08-395). We also thank the Centre for Genetic Control of Mesimvria, Greece for their support.

\section{Supplementary material}

\section{REFERENCES}

Davoli R, Zambonelli P, San-Cristobal M, Scotti E, et al (2007). SNPs and Microsatellite Markers for Genetic Diversity Study in Italian Pig Breeds. In: 6th International Symposium on the Mediterranean Pig (Nanni CL, Zambonelli P and Russo V, eds.). Messina Capo d'Orlando (ME), Italy, 46-53.

Druml T, Salajpal K, Dikic M, Urosevic M, et al. (2012). Genetic diversity, population structure and subdivision of local Balkan pig breeds in Austria, Croatia, Serbia and Bosnia-Herzegovina and its practical value in conservation programs. Genet. Sel. Evol. 44: 5.

Excoffier L, Smouse PE and Quattro JM (1992). Analysis of molecular variance inferred from metric distances among DNA haplotypes: application to human mitochondrial DNA restriction data. Genetics 131: 479-491.

Fabuel E, Barragan C, Silio L, Rodriguez MC, et al. (2004). Analysis of genetic diversity and conservation priorities in Iberian pigs based on microsatellite markers. Heredity 93: 104-113.

Falush D, Stephens M and Pritchard JK (2003). Inference of population structure using multilocus genotype data: linked loci and correlated allele frequencies. Genetics 164: 1567-1587.

Fan B, Wang ZG, Li YJ, Zhao XL, et al. (2002). Genetic variation analysis within and among Chinese indigenous swine populations using microsatellite markers. Anim. Genet. 33: 422-427.

FAO (1998). Secondary Guidelines for Development of National Farm Animal Genetic Resources Management Plans. Management of Small Populations at Risk, Rome.

FAO (2006). The State of the World's Animal Genetic Resources for Food and Agriculture. First Draft, Rome.

FAO (2007). The State of the World's Animal Genetic Resources for Food and Agriculture. FAO, Rome.

FAO (2008). The State of the World's Animal Genetic Resources for Food and Agriculture. Rome. Data accessed on March 26, 2012.

Groeneveld LF, Lenstra JA, Eding H, Toro MA, et al. (2010). Genetic diversity in farm animals - a review. Anim. Genet. 41 (Suppl 1): 6-31.

Guastella AM, Criscione A, Marletta D, Zuccaro A, et al. (2010). Molecular characterization and genetic structure of the Nero Siciliano pig breed. Genet. Mol. Biol. 33: 650-656.

Kalinowski ST (2005). hp-rare 1.0: a computer program for performing rarefaction on measures of allelic richness. Mol. Ecol. Notes 5: 187-189.

Kalinowski ST and Taper ML (2006). Maximum likelihood estimation of the frequency of null alleles at microsatellite loci. Conser. Genet. 7: 991-995.

Laliotis V (2001). A study of pig breeding system in the field. Nagref p40.

Laval G, Iannuccelli N, Legault C, Milan D, et al. (2000). Genetic diversity of eleven European pig breeds. Genet. Sel. Evol. 32: 187-203.

Li SJ, Yang SL, Zhao SH, Fan B, et al. (2004). Genetic diversity analyses of 10 indigenous Chinese pig populations based on 20 microsatellites. J. Anim. Sci. 82: 368-374.

Michalakis Y and Excoffier L (1996). A generic estimation of population subdivision using distances between alleles with special reference for microsatellite loci. Genetics 142: 1061-1064.

Nei M (1978). Estimation of average heterozygosity and genetic distance from a small number of individuals. Genetics 89: 583-590.

Nidup K and Moran C (2011). Genetic diversity of domestic pigs as revealed by microsatellites: a mini review. Genomics Quant. Genet. 2: 5-18. 
Ollivier L (2009). European pig genetic diversity: a minireview. Animal 3: 915-924.

Peakall ROD and Smouse PE (2006). Genalex 6: genetic analysis in Excel. Population genetic software for teaching and research. Mol. Ecol. Notes 6: 288-295.

Pritchard JK, Stephens M and Donnelly P (2000). Inference of population structure using multilocus genotype data. Genetics 155: 945-959.

Raymond M and Rousset F (1995). GENEPOP (version 1.2): population genetics software for exact tests and ecumenicism. J. Hered. 86: 248-249.

Rodrigáñez J, Barragán C, Alves E, Gortázar C, et al. (2008). Genetic diversity and allelic richness in Spanish wild and domestic pig population estimated from microsatellite markers. Span. J. Agric. Res. 6: 107-115.

SanCristobal M, Chevalet C, Haley CS, Joosten R, et al. (2006). Genetic diversity within and between European pig breeds using microsatellite markers. Anim. Genet. 37: 189-198.

Scali M, Vignani R, Bigliazzi J, Paolucci E, et al. (2012). Genetic differentiation between Cinta Senese and commercial pig breeds using microsatellite. Electron. J. Biotech. 15: 1.

Wang JY, Guo JF, Zhang Q, Hu HM, et al. (2011). Genetic diversity of Chinese indigenous pig breeds in Shandong Province using microsatellite markers. Asian Aust. J. Anim. Sci. 24: 28-36.

Weir BS and Cockerham CC (1984). Estimating F-statistics for the analysis of population structure. Evolution 38: 13581370.

Yeh F, Boyle T, Rongcai Y, Ye Z, et al. (1999). Popgene Version 1.31. Microsoft Window-Based Freeware for Population Genetic Analysis. University of Alberta and Tim Boyle, Centre for International Forestry Research, Canada. 